\title{
A bizarre cause of gastric outlet obstruction
}

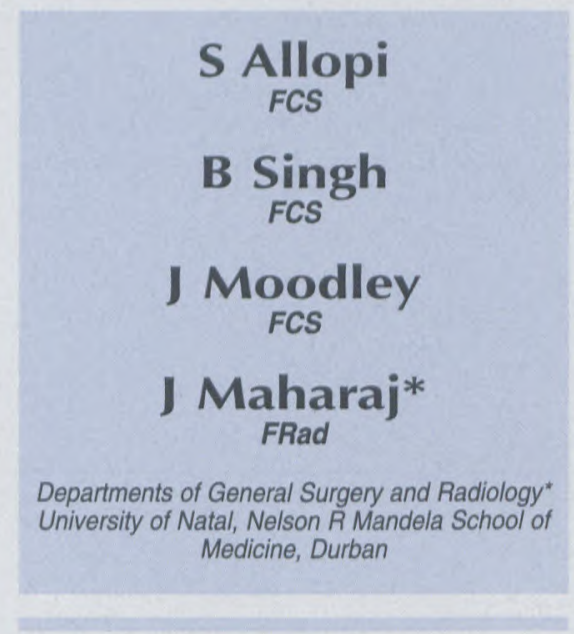

Abstract

Gastric outlet obstruction (GOO) is invariably consequent upon intrinsic gastroduodenal pathology. Ingested foreign bodies are rarely considered to be a cause of this condition. We report possibly the first case of $\mathrm{GOO}$ caused by metallic foreign bodies occluding the pyloro-duodenal junction.

\section{Case report}

A 40-year-old inmate of a mental sanatorium was referred with epigastric pain of 2 weeks' duration, postprandial vomiting and loss of weight of 6 weeks' duration. Apart from being treated for schizoprenia, there was no history of peptic ulcer disease or other medical ailments. At the sanatorium, he did duty in the workshop.

On examination, the patient was found to be dehydrated. The systemic examination, including abdominal examination, was normal.

Biochemical evaluation revealed a mild hypochloraemic metabolic alkalosis, in keeping with GOO.

In view of the clinical suspicion of GOO, upper endoscopy was performed; this revealed several metallic objects tamponading the pylorus of a capacious stomach. Endoscopic retrieval of these foreign bodies was unsuccessful. Presence of these metallic objects was confirmed on plain abdominal X-rays (Fig. 1), and their location was confirmed using barium contrast study.

At surgery, a contained perforation of the anterior gastric wall was noted; a total of 15 metallic objects

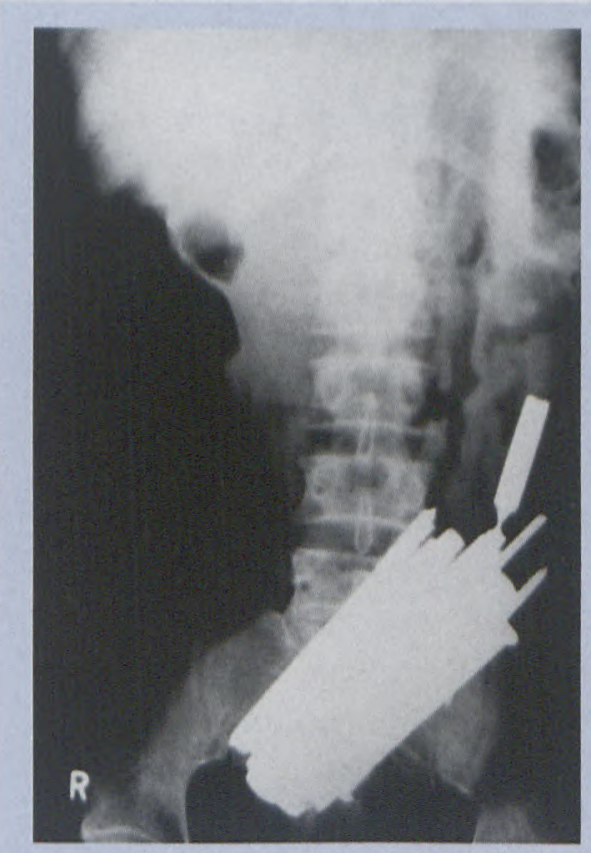

Fig. 1. Plain abdominal radiograph demonstrating cluster of metallic foreign objects lodged along pyloro-antral region of a capacious stomach.

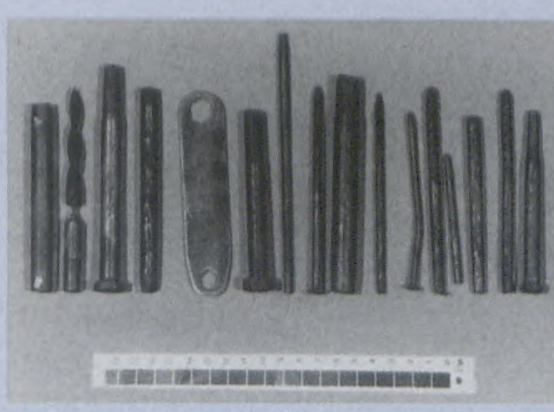

Fig. 2. Metallic objects (weighing $678 \mathrm{~g}$ ) retrieved via gastrotomy.

ranging in length from 5 to $15 \mathrm{~cm}$ were dislodged from the antropyloric region via gastrotomy. These objects weighed a total of $678 \mathrm{~g}$ (Fig. 2). The stomach was noted to be grossly dilated.

The patient's postoperative recovery was uneventful, with satisfactory resolution of his presenting complaints.

\section{Discussion}

Chronic peptic ulcer disease is arguably the most likely cause of GOO. Untreated or unsuspected peptic ulcer disease accounts for up to $10 \%$ of GOO. Other causes include distal gastric cancer and benign strictures (of the antropyloro-duodenum) caused by caustic injury, tuberculosis or Crohn's disease.

Foreign bodies causing $\mathrm{GOO}$ are extremely rare. Possibly the most recognised gastric foreign body is the bezoar, a tightly packed mass of fruit or vegetable matter, hair or other material that forms in the gastrointestinal tract. Most bezoars form in the stomachs of patients with impaired gastric emptying due to effects of previous gastric surgery or other conditions associated with gastric stasis. ${ }^{1,2}$ Bezoars are usually radioopaque. Given the tendency for these to increase in size, removal is effected 


\section{CASE REPORT}

by means of gastrotomy.

Eighty per cent of foreign bodies in the upper gastro-intestinal tract occur in paediatric patients, followed by edentulous adults, prisoners and psychiatric patients. ${ }^{3}$ Most objects (80 - 90\%) pass spontaneously, but 10 $20 \%$ have to be removed endoscopically, and about $1 \%$ require surgery. ${ }^{4,5}$ Objects thicker than $2 \mathrm{~cm}$ and longer than $5 \mathrm{~cm}$ tend to lodge in the stomach. ${ }^{6} \quad$ Long foreign bodies $(>10 \mathrm{~cm})$ tend to lodge in the duodenum, where perforations may devel- op. In addition to causing ulceration, bleeding and perforation, it is conceivable that they predispose to GOO, as demonstrated in this patient.

The spectrum and size of the foreign body noted on the imaging studies served as the reason for our early recourse to surgery, rather than anticipating the spontaneous passage of these foreign bodies.

Recurrent episodes of foreign body ingestion may occur, especially in prisoners, psychiatric patients and patients with peptic strictures.

\section{References}

1. Goldstein SS, Lewis JH, Rothstein R. Intestinal obstruction due to bezoars. Am J Gastroenterol 1984; 79: 313-318.

2. Mir AM, Mir MA. Phytobezoar after vagotomy with drainage or resection. Br J Surg 1973; 60: 846-849.

3. Webb WA. Management of foreign bodies of the upper gastrointestinal tract. Gastroenterology 1988; 94: 204-206.

4. Schwartz GF, Polsky HS. Ingested foreign bodies of the oesophagus. Ann Surg 1985; 51: 173 178.

5. Perelman $\mathrm{H}$. Toothpick perforation of the gastrointestinal tract. J Abdom Surg 1962; 4: 51-53.

6. Kock H. Operative endoscopy. Gastrointest Endosc 1977; 24: 65-68. 